\title{
THE DEVELOPMENT OF WRITTEN COMMUNICATION TRANSVERSAL COMPETENCY IN THE EDUCATION IN MATHEMATICS FOR GRADES 1-4 \\ Maria Temnikova ${ }^{1}$
}

Abstract: Communicational transversal competency represents an important part of the mathematical knowledge, skills and competencies in the process of students' development in Grade 1-4.

The creation and formation of communicational transversal competency helps to put students into an active cognitive position in the course of pedagogical interactions in mathematics classes. Further, creation of communicational transversal competencies develops not only students' analytic - synthetic activity during the process of solving different types of mathematical tasks but also their creative thinking.

This longitudinal research presents some theoretical concepts related to the transversal communicational competency and to its development during the educational process in mathematics in Grade 1-4.

During this empirical study a completely new methodology system of work was developed with the purpose to facilitate development of mathematical knowledge, skills and competencies including the communicational transversal competency. The new system was tested and applied during the compulsory, additional and extended classes in mathematics in Grade 1-4 and consequently was improved after the performance of entry and intermediate diagnostic. Also, this article presents some of the mathematical tasks included in the tests.

The researcher studied the objectiveness, the validity and the reliability of the diagnostic tools developed for the purpose as well as the tasks included in the tests in respect of their difficulty and separating force.

The presented results of the experimental work were processed using mathematics-statistics methods.

UDC Classification: 37.01, DOI: https://doi.org/10.12955/pss.v1.78

Keywords: communicational transversal competency, methodology system of work

Over the last decade the education in Primary school in Bulgaria, Europe and many other countries all over the world aimed at a wider application of the competency approach in the direction of development of competences and competencies in students. In the very foundation of this approach lay the terms competences and competencies. The modernization of the Bulgarian education system is strongly connected to the key terms competences and competencies. The contemporary concept for education considers them as a priority.

For Hutmacher (1996) one of the five key competences which young Europeans need to be furnished with is the competence related to verbal and written communication.

The European referent frame for studying during the entire lifetime endorsed eight competencies which represent part of the recommendation given by the European Parliament and the Council of the European Union. One of them is competency in mathematics.

A number of foreign and Bulgarian authors differentiated the two separate concepts - competences and competencies: Zhoukov (2004) and others.

Establishing the concept that the "key to understanding the competency is the development of an individual approach". Delibaltova (2003) underlined that a certain competency is necessary in order to acquire knowledge and skills. After acquiring these skills and knowledge they become a foundation for our new competency or lead to an increase of the level of this same competency.

In 1996 B. Ray studied the problem related to transversal competencies and wrote that "every competency is actually restricted and is related to a particular object, therefore is related to a certain area meaning that the competency includes transversality" (Ray, 1996, p.4). The author also noted that "transversality - this is the simultaneity which exists between multiple situations because of their common meaning transferred to them by the subjects. This simultaneity is nothing else but intention" (Ray, 1996, p.169).

Merdzanova studied transversal competency-intention as "a point of view, as an approach, as a manner, as style" and underlined that it "can and must be developed pedagogically and to be transferred through different ages and activities" (Merdzanova, 2005, p. 62).

\footnotetext{
${ }^{1}$ Trakia University, Faculty of Education, Stara Zagora, Bulgaria, mpt66@abv.bg
} 
This research studied the process of development of one of the four main transversal competencies determined by Ray and namely the verbal and written communicational transversal competency during education in mathematics for Grades 1-4.

Ray refers the following skills to the written communication transversal competency: "understanding the advices and the instructions in written guidance for work; to prepare and expose in writing the

arguments for his answers, etc.” (Merdzanova, 2002, p. 134).

During the analysis of different pedagogy literature, it was found that there are a number of publications related to the methodology of education. "Generally speaking, the methods of education can be determined as a way of joint interaction between the teacher and the students through which they acquire pedagogically adapted social experience" (Petrov, 2016, p.213). There are different classifications for these methods. For the purposes of this research these methods are separated based on reproductive and productive ones. The first type refers to applying reproductive (direct) strategies and the second one -to problem-productive (indirect) strategies for education in mathematics in Primary school.

L. H. Clark and I. S. Starr consider the act of decision making regarding which method to apply as a core factor in the art of teaching (Clark and Starr, 1986, p.53). There are four parameters that determine the limits within which one can apply the chosen methods for each concrete didactic situation. These parameters are: "the potential opportunities offered by the educational content; the actual level of knowledge on the subject possessed by the students; the level of methodology qualification of the teacher and the cognitive potential of the students determined by their ability to apply the main approaches of the act of education" (Mochalova, 1979, p.73), (Chavdarova et al., 2012, p. 308-309)

The above described written communication transversal competency was studied in respect to the knowledge and skills that students develop as a result of solving different types of mathematical tasks during education in mathematics in Primary school.

The aim of this study is to systemize and present theoretical concepts regarding the written communication transversal competency on the basis of which to design a methodology system of work as well as to study the degree of its development during the course of education in mathematics in Grades $1-4$.

The object of this study is the process of education in mathematics in Grades 1-4.

The subject of this study is the contribution of the combined reproductive and productive strategies that have been used, their relevant work approach for development of the written communication transversal competency in the education in mathematics in Grades 1-4 within the framework of the new methodology system of work.

For the purposes of this empirical study the following criteria were introduced: knowledge and skills given in the written instructions to the mathematical tasks; knowledge and skills to identify (distinguish) the information given in a text task and to write down given and searched units; knowledge and skills to write down the answer of a text task; knowledge and skills to cooperate with other students in writing and work productively as a team on a given mathematical task.

The new methodology system of work is applied and tested for a period of 6 years during compulsory classes in mathematics in Grades 1-4. After this period the tasks from the system were included in the compulsory educational content of one of the following mathematics textbooks (approved by the Ministry of Education of Republic of Bulgaria) for: Grade 1 (Bogdanova, Temnikova, 2016), Grade 2 (Bogdanova et al., 2017), Grade 3 (Bogdanova et al., 2018) and Grade 4 (Bogdanova et al, 2019). The new methodology system of work incorporates a series of mathematical tasks purposefully used for the development of not only the mathematical competency but also of the written communication transversal competency. During the application of the new system in the education of mathematics in Primary school a combination between the multiple-theoretical, human-personal, technological, taxonomy, activity oriented and the competency approaches is used.

As reproductive methods within the new methodology system of work one can use reproductive discussion, exercises by example, telling a story, explanation, demonstration, or observation. Examples of productive methods of work are problem presentation, problem-searching (heuristic) discussion, variative, creative and problem-searching exercises, modelling, analytic-synthetic method, comparison, analogy, solving problem tasks per analogy, heuristic (partially research) method, situation method, or 
a method of incidents and causes (Temnikova, 2018). Nowadays the education in mathematics in the Republic of Bulgaria is aimed at the development of knowledge, skills and competencies from competency clusters "Numbers", "Geometry figures and bodies", "Measuring" and "Modelling". In parallel, suitable conditions for the development of written communication transversal competency can be created as well.

Development of written communication transversal competency depends on the way the mathematics classes are carried out and on the complexity of activities which students perform in relation to the educational content. This is the reason why the overall development of the new system of education requires changes not only in the educational content but also in the applied methods of education. The new methodology system of work incorporates combined application of productive and reproductive methods.

Some of the mathematical tasks included in the system are presented below. For solving the tasks for Grade 1 (Bogdanova, Temnikova, 2016, p.29) initially a reproductive discussion is used for clarifying the components given in the text of the task - length of the little mole and of the little mouse without a tale - respectively $20 \mathrm{~cm}$ and $7 \mathrm{~cm}$.

Task: The length of a little mole without its tale is $20 \mathrm{~cm}$, and the length of a little mouse without its tale is $7 \mathrm{~cm}$.

\begin{tabular}{|l|l|l|l|}
\hline Figure 1: Picture visualizing the task for Grade 1 \\
\hline Source: Bogdanova et al., 2016 & & \\
\hline
\end{tabular}

To which question one can reply with the numerical expression: $20-7=$ $(\mathrm{cm})$

The following productive methods were applied: creative exercise, modelling and heuristic discussion. Through the method of modelling the teacher develops an auxiliary model. Analyzing the model students find the relation with the picture where the animals are placed on the centimeter ruler.

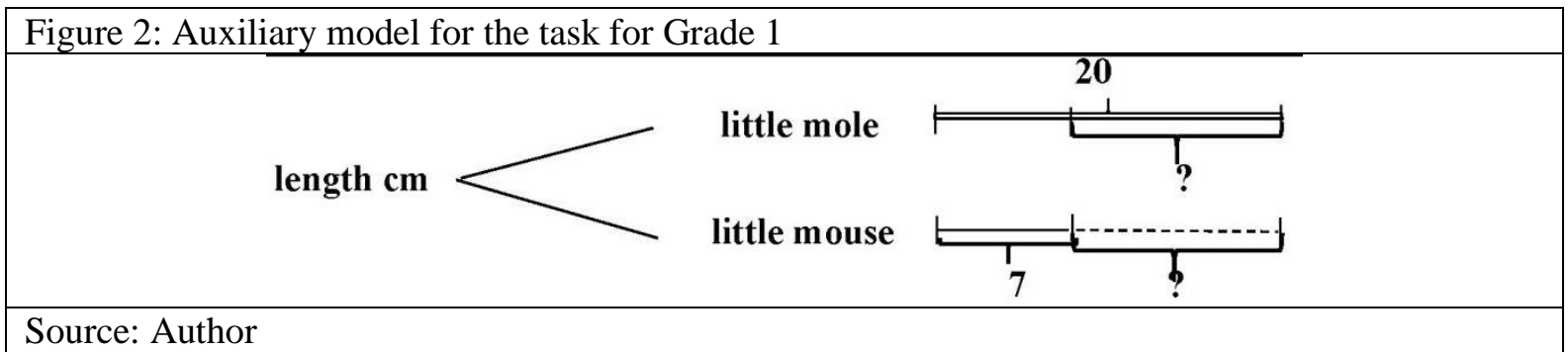

Through a heuristic discussion the teacher and the students clarify the searched components of the mathematical task - they have to formulate the question in the text task whose reply is the mathematical numeric expression $20-7=\ldots$. The students use the auxiliary model (drawing) for visual support in order to resolve the problem situation. During the discussion the relation between the auxiliary model and the numerical expression becomes evident. As deduction is used in the numerical expression, students get to the conclusion that potentially there could be two questions: "How many centimeters is the mole longer than the mouse?" and "How many centimeters is the mouse shorter than the mole?" They also get to the conclusion that using one and the same numerical expression two different text tasks can be solved - to find a number bigger than a given one with several units and to find a number smaller than a given one with several units.

Below is presented one of the mathematical tasks for Grade 2 included in the newly developed methodology system of work:

"Teo has got six tennis balls and Monny - 4 times more. How many tennis balls have got the two of the them?" Please outline the drawing that corresponds to the respective task. Solve the task. (Bogdanova et al., 2017, p. 11) 


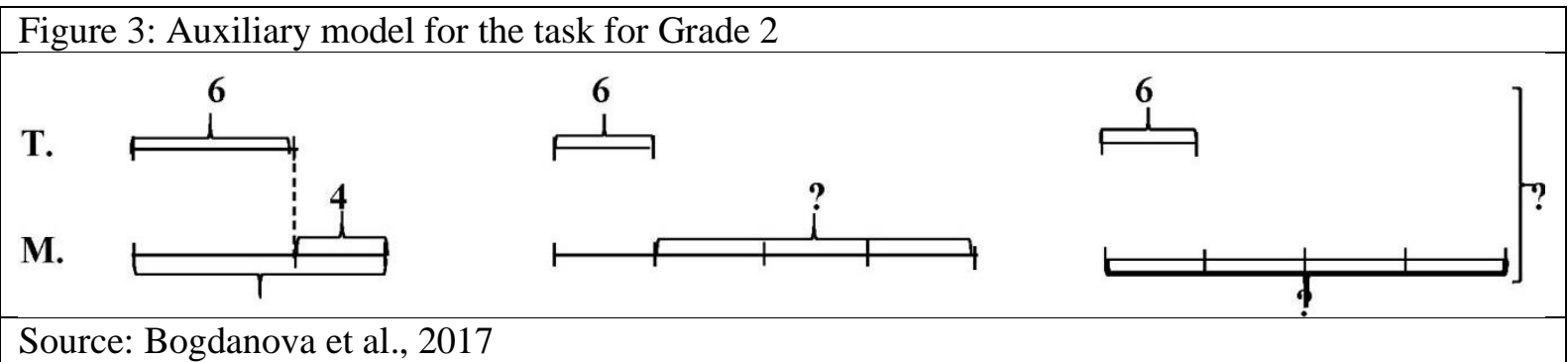

This composite text task is related to finding a number which is several times bigger than a given one and explains the nature of mathematical addition. Initially the new methodology system of work foresees the use of the reproductive method of discussion through which the given and the searched components of the task are identified.

A problem situation for the Grade 2 students is to determine which drawing corresponds to the task and consequently to solve the task. They use in combination the reproductive methods demonstration and observation as well as the productive methods modelling, problem exposition and problem-searching discussion. Analysis of the auxiliary models facilitates the process of development in the students of knowledge and skills to work with such models. It was found out that drawing No.3 is the one that corresponds to the solution of the text task $-6+4.6=$. Through analytic-synthetic activity the students explain why the first two drawings cannot be related to the solution of the task. The second graders are additionally asked to compose text tasks according to the first two auxiliary models (drawings) and to solve them.

Poya identified four stages during solving of a text task. In the next task (Bogdanova et al., 2018, p.11) using the modelling method a slightly different model was created as it refers to the depth of rivers. The work with this model represents a problem situation for third-grade students.

Task: In an encyclopedia for children is written that the biggest river depth in the world was measured in the rivers Danube, Yangtze and Congo. Using the data from the drawing please find how many meters is the depth measured in the rivers Congo and Yangtze. What is the ranking of the river Congo depth in comparison with the depth of the other two rivers? What is the ranking of the Danube river depth?

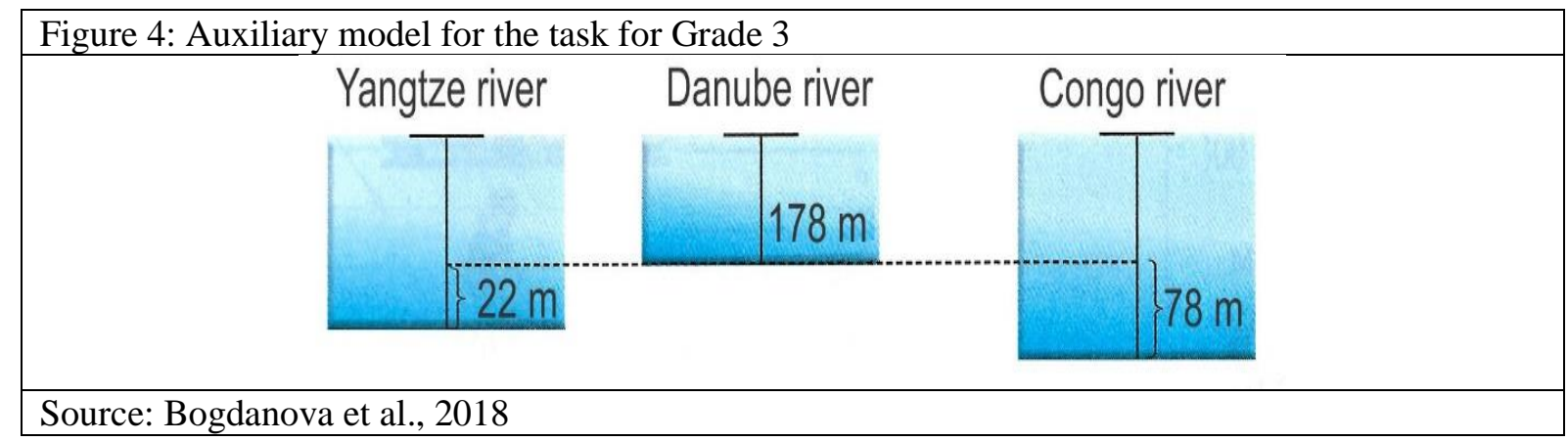

Using reproductive discussion, the students and the teacher identify the given task and the searched components of the text task. In combination with the reproductive discussion they use the following productive methods in addition to modelling: problem presentation, problem-searching discussion and creative exercise.

With the help of the above described methods and after performing analytic-synthetic activity during their work with the models, students find out that the Yangtze river is $22 \mathrm{~m}$ deeper than the Danube river and the Congo river is $78 \mathrm{~m}$ deeper than the Danube river. The next part of the work is related to composing mathematical numerical expressions by the students for finding the depth of the two rivers.

The current educational programs for Grade 3 and 4 of the Primary school allow solving text tasks with indirect use of relations. Below is one of the tasks for Grade 4 which is included in the newly developed methodology system of work (Bogdanova et al., 2018, p. 37):

Task: Vlado and his father have gone to the mountains for 3 days. The third day they walked $10550 \mathrm{~m}$, the second day $-2300 \mathrm{~m}$ more than the third day which is $4650 \mathrm{~m}$ less than the distance they walked during the first day. How many meters they walked during the three days in total? 
The text task is composed (it is solved with more than one arithmetic action) with direct use of the relation "more", indirect use of the relation "less". For clarifying the distance walked by Vlado and his father during the third and the second day the teacher uses reproductive discussion. The distance walked during the first day is given in the text through indirect use of the relation "less". Its analysis represents a problem situation for the students. For the purposes of clarifying it and for drafting a plan for solving the text task the following productive methods are used: creative exercise, problem exposing, modelling and problem-productive discussion. It will be the teacher's decision to make an auxiliary model using the method of modelling in order to facilitate composing numerical expressions needed for solving the task.

The experimental work was carried out during 2019 - 2020 with students from two Grade 4 classes from the Petko Rachov Slaveykov Primary school, of the Town Stara Zagora - one experimental and one referent class. The researcher applied in the experimental class the newly developed methodology system of work in the education of mathematics. The empirical research used two tests and studied their objectiveness, validity and reliability as well as their difficulty and the separating force of the mathematical tasks included in them. The test results were processed with the use of mathematicalstatistical methods. The entry diagnostic discovered that the students from both classes have a similar level of knowledge and skills in relations to the chosen criteria. The results of the exit diagnostic are shown in Figure 5 below.

\begin{tabular}{|r|r|l|l|l|l|}
\hline \multicolumn{2}{|c|}{ Figure 5: Exit diagnostic for knowledge and skills of the students } \\
\hline & & & & & \\
\hline
\end{tabular}

Source: Author

As a result of the exit diagnostic it became evident that there is a significant difference in respect of the level of knowledge and skills of the students from both classes to recognize (separate) the data given in a text task and to write down the given and searched units. The number of students from the experimental class who worked correctly is $23 \%$ higher than the number of students from the referent class. The number of students from the experimental class who wrote down correctly the answers of the text tasks from the exit diagnostic test is $27 \%$ higher than the number of students from the referent class. The level of knowledge and skills of the students from the experimental class to correctly cooperate in a written form and to productively work in a team in mathematics classes is $13.3 \%$ higher than the level of knowledge and skills of the students from the referent class.

\section{Conclusions}

The use of the newly developed methodology system of work in the education in mathematics for Grades 1-4 as well as the reproductive and the productive methods included in it, facilitated the achievement of the following:

-The development in Primary school students a higher level of knowledge and skills related to competency cluster "Modelling", written communication transversal competency and mathematical competency; 
-Lead students to perform productive activity related to the preparation of summaries, abstractions as well as the independent use of the acquired knowledge while solving different mathematical tasks;

-Lead to the creative application of knowledge and development of creative personality in the students. The use of the newly developed methodology system of work in the education in mathematics for Primary school creates opportunities for: change in the nature of the educational content - from a purpose to a tool for acquiring skills for self-realization and for development of written communication transversal competency; to the development of skills in students to cooperate with their classmates, to improve themselves, to creatively organize their activities during task solving process, to deploy their own initiative and independent action while solving various types of mathematical tasks; to students developing skills for reflective behavior related to planning, regulation and control of their own action.

\section{References}

Bogdanova,M., M. Temnikova, (2016). Tetradka № 2 po matematika za parvi klas [Notebook No.2 in mathematics for Grade 1], Sofia, Bulgaria: Klet, Bulvest 2000 Publisher, 29.

Bogdanova M., M. Temnikova, V. Ivanova, (2017). Tetradka № 3 po matematika za vtori klas [Notebook No.3 in mathematics for Grade 2], Sofia, Bulgaria: Klet, Bulvest 2000 Publisher, 11.

Bogdanova, M., M. Temnikova, V. Ivanova, (2018). Tetradka № 2 po matematika za treti klas [Notebook No.2 in mathematics for Grade 3], Sofia, Bulgaria: Klet, Bulvest 2000 Publisher, 11.

Bogdanova, M., M. Temnikova, V. Ivanova, (2018). Tetradka № 1 po matematika za chetvarti klas [Notebook No.1 in mathematics for Grade 4], Sofia, Bulgaria: Klet, Bulvest 2000 Publisher, 37.

Clark, L. H., I. S. Starr, (1986). Secondary and Middle School Teaching Methods, 5-th ed., Macmillan Publishing Co., NY, 53

Delibaltova, V. (2003). Kam kompetentnostta kato obekt na didakticheski interes [To the competency as an object of didactic interest], Pedagogy magazine, XIII, № 2. Sofia.

Hutmacher,W. (1996). Key Competencies in Secondary Education for Europe: Sypmosium on „Key Competencies in Europe“, Berne (Switzerland) 27-30 March, General Report

Kostova, S. Ch., B. Delibaltova, B. Gospodinov, (2012). Pedagogika [Pedagogy], University editor "St. Kliment Ohridsky", Sofia, 308-309.

Merdzhanova Y., (2005). Multisensory principle in education and in life, Sofia, 62, 134.

Mochalova, N. M. (1979). Medodij problemnogo obucheniya i granitsi ih primeneniya, [Models of problem education and limits of their application], Kazan, 73

Petrov, P. D., (2016). Contemporary didactics, Avangard Prima editor, Sofia, 213.

Ray, B. (1996). Les competences transversals en question, Paris, ESF, 4, 196.

Zhukov, Y., A. Erpfeev, S. Liptov (2004). Methods of practical social psychology, Moskow. 